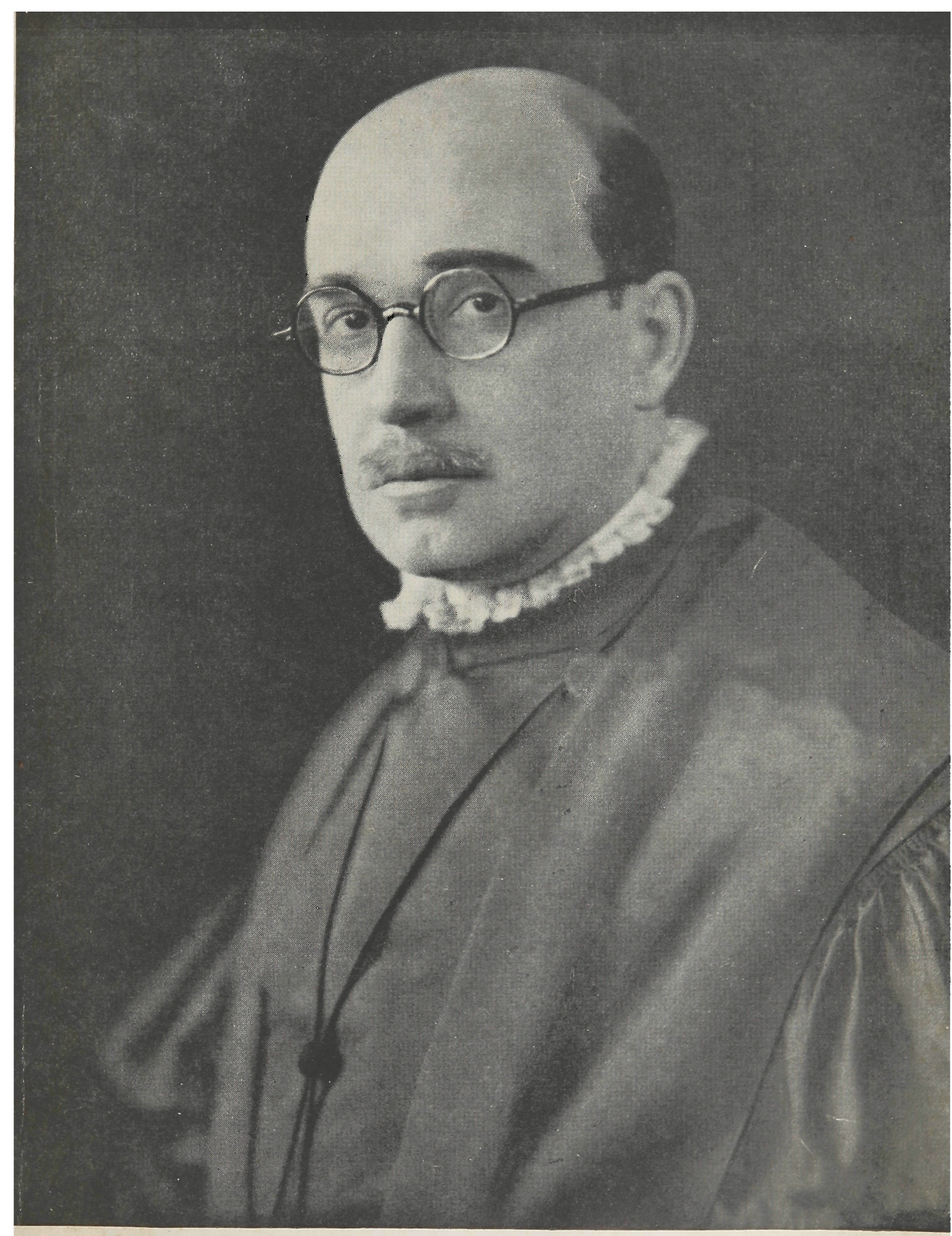

Drafessar Dr. 7. I. Cardara de Mela neta 


\section{Professor J. J. Cardozo de Melo Neto}

Redação

1 - O professor José Joaquim Cardozo de Melo Neto nasceu em São Paulo, aos 19 de julho de 1883, filho do dr. José Joaquim Cardozo de Melo Junior, ex-juiz de direito e ex-chefe de polícia da Capital de São Paulo no Império, e, ainda hoje, advogado em nosso fôro.

Professor primário aos 16 anos de idade, no Grupo Escolar da Bela Vista, matriculou-se, em 1901, na Faculdade de Direito e formou-se bacharel a 26 de agosto de 1906 . Sua vida de estudante foi prestigiosa, como atesta a circunstância de ter sido, durante o curso, presidente do Círculo Jurídico Acadêmico.

Logrando ser classificado em primeiro logar em concurso para professor substituto da quinta seção da Faculdade de Direito, foi nomeado a 11 e empossado nesse cargo a 18 de outubro de 1917, data em que recebeu gráu de doutor em direito. Passou logo a exercício efetivo das cátedras de "Economia Política e Ciência das Finanças" e de "Direito Administrativo e Ciência da Administração", dado afastamento eventual dos professores Manuel Pedro Villaboim e Dario Ribeiro.

A 2 de dezembro de 1920, foi nomeado professor catedrático de Economia Política e Ciência das Finanças. Conserva, desde que a Ciência das Finanças foi destacada, como cadeira autônoma, a de Economia Política.

Ocupou interinamente, durante vários anos, a cátedra de Direito Administrativo, até a nomeação do professor Mario Masagẽo, seu antigo aluno.

2 - Político militante, foi um dos fundadores da Liga Nacionalista e, em 1926, do Partido Democrático, no qual 
exerceu função diretora. Prefeito da capital em 1930, deputado à Assembléia Nacional Constituinte e sub-lider da bancada paulista em 1935 e 1936, deputado federal, lider da bancada do Partido Constitucionalista e relator da Receita na Comissão de Finanças da Câmara de Deputados, coube-lhe, em 1937, ser governador do Estado de São Paulo e em 1938 , interventor federal.

E', hoje, diretor da Faculdade de Direito.

Dedica-se a atividades forenses. Foi um dos fundadores do Instituto da Ordem dos Advogados de São Paulo, e da S. A. Central Elétrica Rio Claro e Francana de Eletricidade; e, atualmente, diretor-presidente do Banco Mercantil do Estado de São Paulo.

3 - Na cadeira de Economia Política adota o conceito de Macleon sobre o conteudo da matéria: "A Economia Política é a Ciência das trocas". Segue ele o grande economista nos conceitos básicos de produção, trabalho, valor, preço, capital, moeda, como o fazia tambem Almeida NoGueira. Entendendo, embora, que ha leis econômicas naturais, adverte, porém, que ao lado destas, atuam leis simplesmente históricas, no sentido da Escola Histórica. O descrédito em que caiu a noção de lei natural econômica provém do exagêro dos clássicos em considerar naturais muitas relações econômicas que apenas regem um dado momento histórico.

O eminente professor diverge, entretanto, de MAcLeod e de Almfina Noguerra no que concerne à tarefa econômica do Estado. Sua orientação sempre foi a do meio termo entre o individualismo liberal e o socialismo de Estado. Legítima proclamava, desde 1917, como proclama, a interferência do Estado na ordem econômica, variavel segundo as circunstâncias o exigirem, de tempo e de lugar, maior aquí, menor ali, mas devendo ser, hoje, no Brasil, bastante intensa, na medida da satisfação do momento histórico que atravessamos.

Segundo escreveu na dissertação, para o concurso ao logar de professor substituto, em 1917, intitulada “A ação 
social do Estado": "o Estado para cumprir a sua missão, não se pode limitar ao papel de defensor do direito entre os associados" (pág. 4 e 5); "tem ao lado de uma missão jurídica, uma missão social, embora contingente". As regras dessa contingencia é que o autor as expõe, então, a propósito "da ação social do Estado quanto ao desenvolvimento da população", "em relação à saude pública", “à instrução e educação", e, afinal, "na ordem econômica". Para ele, no que concerne à produção, a regra de que "o Estado não deve fazer o que um particular pode fazer" não é sem exceção.

"Quer-nos parecer - conclue - que, tanto quanto permitiram as nossas limitadas forças, mostramos até onde vai e onde deve parar a atividade social do Estado. A enumeração dos casos, entretanto, não pode deixar de considerar-se meramente exemplificativa, tão variada e crescente se vem manifestando a atividade social no Estado moderno.

Sintetizando, podemos dizer:

O Estado exerce ao lado da sua atividade jurídica, uma atividade social. Ao Estado é impossivel circunscrever a sua esfera de ação à atividade jurídica. Aliás, a concepção individualista do Estado não teve jamais correspondente na realidade objetiva, não se limitando a tutela do direito. $O$ Estado agiu sempre no sentido de promover o bem estar e a prosperidade sociais.

A interferência do Estado, para ser legítima, precisa basear-se no interesse comum. Subordinada a este critério, ela facilita o exercício da atividade jurídica.

A atividade social não se confunde, porém, com o socialismo em qualquer das suas manifestações.

Os limites da atividade social são traçados pela apreciação do fim do ato a ser praticado.

Se $o$ ato tem fins coletivos, se promove o bem comum, se a todos aproveita, ele se compreende na esfera da atividade social do Estado.

Se, ao contrário, o ato pode ser praticado pelo particular tão bem como pelo Estado, ou aproveita apenas a uma 
classe de indivíduos, ele escapa às atribuições do Estado, que é unicamente órgão de interesses verdadeiramente gerais e públicos".

4 - São de sua autoria tambem, entre outros, os trabalhos seguintes: "O ante-projeto do novo programa do Partido Democrático", "Diário de São Paulo", 11-6-1932; "Carteira de redescontos - Projeto apresentado à Comissão de Finanças", "Jornal do Brasil", Rio, 14-11-1935; "O centenário de José Bonifácio, o moço", "Pandectas Brasileiras", Rio, 1937, vol. 3. , 5. ${ }^{a}$ parte, pág. 92; "Da constitucionalidade do imposto sobre a renda", "Revista dos Tribunais", São Paulo, 1926, vol. 57, pág. 630; "Crédito internacional - Empréstimos externos do Estado de São Paulo - Cambio negro", (Parecer), in-“Documentos elucidativos do Inquérito do Instituto de Café do Estado de São Paulo", 1933, vol. 1. ${ }^{\circ}$; "Sobre nova cunhagem de moedas divisionárias", Projetos da Camara dos Deputados Federais, Rio, 1937, vol. 3. ${ }^{\circ}$, avulso . $^{\circ}$ 12; "Curso didático de economia política", de J. L. de Almeida Nogueira, 5. edição revista, São Paulo, 1936; "Em defesa dos cabeças do movimento de 5 de julho de 1924 Delitos políticos - Inconstitucionalidade do decreto que tira o seu julgamento do tribunal do juri e entrega ao juiz singular", São Paulo, 1925; "Discriminação de rendas entre a União e os Estados" (Dissertação apresentada à Faculdade de Direito de São Paulo), sem data, 1 vol.; "Discurso de saudação ao Professor Almeida Junior", "Revista da Faculdade de Direito", São Paulo, 1941, vol. 36, pág. 307; "Discurso proferido por ocasião da homenagem que lhe foi prestada pelo Instituto dos Advogados de São Paulo, em virtude de sua investidura no cargo de governador deste Estado", "Revista da Faculdade de Direito", São Paulo, 1937, vol. 33, pág. 123; "Discurso pronunciado em 28 de outubro de 1920, em nome da Congregação da Faculdade de Direito, na recepção solene do professor Orlando", "Revista da Faculdade de Direito", São Paulo, 1936, vol. 32, pág. 105; “Das duplicatas ou contas assinadas", Projetos da Camara dos Deputados Federais, Rio, 1935, vol. 3. ${ }^{\circ}$, avulso n. ${ }^{\circ} 38$; "Economia 
política e ciência das finanças - Discriminação de rendas entre a União e os Estados", (Dissertação apresentada à Faculdade de Direito de São Paulo), São Paulo, 1917; "O funcionamento do Tribunal de Contas", (Parecer), Projetos da Camara dos Deputados Federais, Rio, 1934-1935, vol. 1. ${ }^{\circ}$, avulso n. 52; "Homenagem a Clovis Bevilaqua - A entrega do diploma de professor honorário da Faculdade de Direito de São Paulo ao eminente jurisconsulto", "Revista da Faculdadie de Direito", São Paulo, 1937, vol. 33, págs. 370, 373 e 374; "Augusto da Costa, A Nação Corporativa", "Revista da Faculdade de Direito", São Paulo, 1938, vol. XXXIV, fasc. II, pág. 717; "Oração do paraninfo à turma de bachareis de 1938 da Faculdade de Direito de São Paulo", São Paulo, 1929, 1 vol.; "Parecer sobre as "bases para a Federação dos Institutos dos Advogados Brasileiros", adoptadas na Conferência que se realizou, no Rio de Janeiro, a 25, $26,27,28$ e 29 de agosto, na qual tomaram parte os presidentes e representantes dos Institutos dos Advogados do Rio de Janeiro, Minas, Rio Grande do Sul e São Paulo"; "Podem ser tributados pela União os rendimentos dos imoveis rurais e urbanos, bem como das indústrias e profissões?", Trabalhos do Instituto dos Advogados, São Paulo, 1917-1936, pág. 67; "Discurso de agradecimento por ocasião da posse na Diretoria da Faculdade", "Revista da Faculdade de Direito", São Paulo, 1941, vol. 36, págs. 228, 229 e 233; "Saudação ao professor Fernando Emidio da Silva, da Universidade de Lisboa, proferida, em nome da Congregação da Faculdade de Direito da Universidade de São Paulo, na sessão solene de recepção realizada, em 27 de novembro de 1939, na sala "João Mendes", "Revista da Faculdade de Direito de São Paulo”, 1939, vol. 35, pág. 709. 